\title{
A comparative study on selected iron status assessment assays among secondary school students in Bauchi State, Nigeria
}

\author{
Rufai A. Dachi, ${ }^{1}$ Sani Awwalu, ${ }^{2}$ Aliyu D. Waziri, ${ }^{2}$ Kasim M. Pindiga, ${ }^{2}$ Usman M. Abjah, ${ }^{3}$ \\ Abdulaziz Hassan ${ }^{2}$ \\ ${ }^{1}$ Department of Hematology Abubakar Tafawa Balewa University Teaching Hospital Bauchi; ${ }^{2}$ Department \\ of Hematology Ahmadu Bello University Teaching Hospital Zaria Nigeria; ${ }^{3}$ Department of Hematology \\ University of Maiduguri Teaching Hospital Maiduguri Nigeria
}

\begin{abstract}
Iron deficiency anemia (IDA) is the most common form of anemia worldwide, with highest burden in developing countries. The assays used in detecting iron deficiency comprise of red blood cell indices such as Mean Corpuscular Hemoglobin and Mean Corpuscular Volume, serum ferritin, soluble transferrin receptor (STfR) and STfRL-index. Each of these assessment tools has its drawback(s). This study was conducted to assess IDA diagnostic inter-rater agreements between red cell indices, serum ferritin, STfR and STfLF-Index. A cross sectional descriptive study using systematic random sampling of eligible secondary school students in Misau LGA, Bauchi State, Nigeria. Complete Blood Count with cellular indices, serum ferritin and STfR assays were
\end{abstract}

Correspondence: Rufai Abdu Dachi, Department of Hematology and Blood Transfusion, Abubakar Tafawa Balewa University Teaching Hospital, Bauchi Nigeria.

Tel.: +080.34836698

E-mail: rufaidachi@yahoo.co.uk

Key words: Comparative, Iron status, Serum ferritin, Soluble transferrin receptor.

Acknowledgements: the authors want to sincerely acknowledge the support and cooperation of the Bauchi State Ministries of Health and Education as well as the staff and students of the participating schools.

Contributions: RAD, Conceptualization, data acquisition, interpretation, manuscript writing, reference search; SA, Conceptualization, data analysis, interpretation, manuscript writing; $\mathrm{ADW}, \mathrm{AH}$ and UMA, conceptualization, interpretation, manuscript reviewing; KMP, Conceptualization, data acquisition, manuscript review.

Conflict of interests: the authors declare no potential conflict of interest.

Funding: none.

Received for publication: 21 May 2018.

Revision received: 18 October 2018.

Accepted for publication: 18 October 2018.

This work is licensed under a Creative Commons Attribution NonCommercial 4.0 License (CC BY-NC 4.0).

(C)Copyright R.A. Dachi et al., 2018

Licensee PAGEPress, Italy

Annals of African Medical Research 2018; 1:20

doi:10.4081/aamr.2018.20 conducted. Data was analyzed using SPSS version 23.0. Proportions were compared using Z-tests of proportions. Cohen's Un-weighted kappa analyses were used to assess pairwise agreements in the ability of STfLF-Index, serum ferritin, STfR and red cell indices to classify participants into IDA and non-IDA. Level of significance was set at $\mathrm{P} \leq 0.05$. A total of 210 participants were enrolled in the study with females constituting 153 (72.9\%). STfLF-Index, STfR, serum ferritin levels and red cell indices revealed that $130 / 210(61.9 \%), 160 / 210(76.2 \%), 7 / 210(3.3 \%)$ and $112 / 210(53.3 \%)$ respectively had iron deficiency. STfR revealed a significantly higher percentage of students with iron deficiency compared to serum ferritin, STfLF-Index and red cell indices. Assessment of iron deficiency showed concurrence between STfR and STfLF-Index. STfR and STfLF-Index have similar ability in classifying iron status.

\section{Introduction}

Iron deficiency anemia (IDA) is the most common form of anemia worldwide, affecting about 500 million people. ${ }^{1}$ It is particularly prevalent in developing countries with Africa and Asia having the highest burden owing to poor quality of food and worm infestations. ${ }^{2}$ In Nigeria, about $73 \%$ of anemic hospitalized patients are iron deficient. ${ }^{3}$ The most vulnerable groups include adolescents, most of whom are of secondary school age. Factors such as increased physiologic demands, menstrual blood loss in females and increased feto-maternal iron demand during pregnancy have been implicated. ${ }^{4,5}$

Iron status can be assessed using red cell indices, as well as biochemical markers namely; SF, STfR and STfRL-Index. However, these parameters may not change rapidly enough to reflect transient iron deficient states and thus each parameter has its own $\operatorname{drawback}(\mathrm{s}) .6,7$

Mean corpuscular volume (MCV) and mean corpuscular hemoglobin $(\mathrm{MCH})$ do not change in latent iron deficiency until the storage iron is completely depleted ${ }^{8}$ Serum ferritin (SF) on the other hand, has a direct correlation with the storage iron and is commonly employed for the diagnosis of iron deficiency and iron overload. The normal range for SF is between $15-300 \mathrm{ug} / \mathrm{L},{ }^{8}$ with $1 \mathrm{ug} / \mathrm{L}$ of SF representing about $8-10 \mathrm{mg}$ of storage iron. ${ }^{8}$ Values less than $12 \mathrm{ug} / \mathrm{L}$ have been suggested to strongly indicate lack of storage iron. ${ }^{9}$ However, the World Health Organization (WHO) recommends using a cutoff of $<15 \mathrm{ug} / \mathrm{L} .{ }^{10}$ The usefulness of this assay is however limited in inflammation, neoplasia and liver disease as serum ferritin is an acute phase reactant. ${ }^{11}$

Serum transferrin receptor (STfR) level is the concentration of the soluble fragments derived from proteolysis of cell membrane transferrin receptors during red cell maturation. STfR increases in iron deficiency which follows depletion of iron stores. ${ }^{9}$ Unlike SF, 
STfR is not an acute phase reactant; hence its estimation can be helpful in differentiating IDA from anemia of chronic disease (ACD). However, STfR levels are affected by the rate of erythropoiesis, therefore levels are increased in conditions with increased erythropoiesis; such as hemolytic anemias and thalassemias but decreased in conditions associated with marrow hypoplasia. ${ }^{11}$ Serum ferritin reflects the iron in the storage compartment while STfR reflects functional iron compartment, the STfR/log ferritin index (STfLF-Index) has been suggested as a better estimate of body iron compared to SF or STfR alone; thus has been found to increase the diagnostic sensitivity and specificity for diagnosing iron deficiency. ${ }^{12,13}$

This study was conducted to assess inter-rater agreements between red cell indices (MCV and MCH), SF, STfR and STfLFIndex in diagnosing Iron deficiency among non-boarding Secondary School Students in Misau Local Government Area of Bauchi State, North-East Nigeria.

\section{Materials and Methods}

This was a cross sectional descriptive study conducted among secondary school students in Misau Local Government Area (LGA) Bauchi State, North-Eastern Nigeria. The study was conducted from $12^{\text {th }}$ October to $30^{\text {th }}$ November 2016. It was estimated that for each pair of diagnostic tests with a dichotomous outcome (IDA versus no IDA) 212 subjects will be required to achieve an $80 \%$ power at an alpha level of $\leq 0.05$ assuming that frequency of positive ratings (IDA), expected Kappa and non-inclusion rates were $70 \%, 0.60$ and $10 \%$ respectively. ${ }^{14}$ Non-boarding secondary school students were enrolled from all the seven secondary schools in the LGA using systematic random sampling. Signed informed consent was obtained from participants who were $\geq 18$ years, while Parental consent and assent were obtained from participants under 18 years. Students on iron supplements for any reason or a history of blood transfusion in the previous 3 months were excluded from the study.

Using aseptic procedures, $7 \mathrm{~mL}$ of venous blood were collect- ed from each participant and divided into two aliquots. The first aliquot of $3.0 \mathrm{~mL}$ was delivered into sequestrene ( $\left.\mathrm{K}_{2} \mathrm{EDTA}\right)$ bottles for the determination of complete blood count. The second aliquot of $4.0 \mathrm{~mL}$ was delivered into plain bottles, spun at $5000 \mathrm{rpm}$ for 5 minutes to obtain the sera that were used for determinations of SF and STfR levels.

Hematocrit, MCV and MCH were assessed using Sysmex XT 2000i Hematology analyzer by Sysmex Kobe Japan. Serum ferritin and STfR assays were determined using Rayto RT 2100 ELISA machine and Micoplate Reader. STfLF-Index was computed as STfR levels/log Ferritin levels. Monobind Inc. Lake Forest, CA92630.USA Ferritin kit and Human Transferrin Receptor ELISA KIT WKEA Med supplies Comp. Chinghun 130012 China were used.

Anemia was defined as $\mathrm{HCT}<0.36 \mathrm{~L} / \mathrm{L},{ }^{15}$ while either STfLFIndex $>1.36$, STfR $>1.8 \mathrm{mg} / \mathrm{L}$ or SF levels of $<15 \mathrm{ug} / \mathrm{L}$ were considered to indicate iron deficiency (ID). ${ }^{10,16}$ Red cell indices MCV of $<80$ fLand $\mathrm{MCH}$ of $<27 \mathrm{pg}$ indicated the presence of microcytosis and hypochromia. ${ }^{1}$

Data was collated and analyzed using SPSS version 23.0. Categorical variables were reported as percentages while means \pm standard deviation (SD) and medians interquartile ranges (IQR)

Table 1. Profile of study participants.

\begin{tabular}{lc} 
Profile & N. (\%) \\
Sex & \\
Females & $153(72.9)$ \\
Males & $57(27.1)$ \\
Age (years) of participants by sex & \\
$\quad$ Females & $16.1 \pm 1.8$ \\
Males & $16.6 \pm 2.3$ \\
\hline Class & \\
JSS 2 & $27(12.9)$ \\
JSS 3 & $33(15.7)$ \\
SSS 2 & $77(36.7)$ \\
SSS 3 & $73(34.8)$ \\
\hline
\end{tabular}

Table 2. Pairwise comparisons of proportions of IDA diagnosed each assay.

\begin{tabular}{lccc} 
Test 1 (\% of IDA Diagnosed) & \multicolumn{2}{c}{ Z-Test of Proportions } \\
& Test 2 (\% of IDA Diagnosed) & Z-value \\
STfR (76.2) & STfRLF Index (61.9) & 3.2 & 0.002 \\
& Ferritin (3.3) & 15.3 & $<0.001$ \\
STfRLF Index (61.9) & Red Cell Indices (53.3) & 4.9 & $<0.001$ \\
& Ferritin (3.3) & 12.8 & $<0.001$ \\
\hline Ferritin (3.3) & Red Cell Indices (53.3) & 1.8 & 0.075 \\
\hline
\end{tabular}

Table 3. Assay Pairwise Comparisons of Pairwise Inter-rater Agreements for IDA diagnosed.

\begin{tabular}{llcccc} 
Test 1 & Test 2 & Value & $\begin{array}{c}\text { Unweighted Kappa } \\
\text { 95\%CI lower limit }\end{array}$ & 95\%CI upper limit & P-value \\
STfR & STfRLF Index & 0.674 & 0.572 & 0.776 & 0.001 \\
& Ferritin & 0.021 & 0.005 & 0.037 & 0.133 \\
STfRLF-Index & Red Cell Indices & 0.013 & -0.107 & 0.073 & 0.035 \\
\hline \multirow{2}{*}{ Ferritin } & Ferritin & 0.042 & 0.011 & 0.165 & 0.635 \\
\hline
\end{tabular}

Interpretation of Strength of agreement using Unweighted Kappa value: $<0.20=$ poor, $0.21-0.40=$ Fair, 0.41-0.60 = Moderate, 0.61-0.80 = Good, 0.81-1.00 = Very Good. 
were used to summarize normally and non-normally distributed continuous variables respectively. Proportions were compared using Z-tests of proportions. Cohen's Un-weighted kappa analyses were used to assess pairwise agreements in the ability of STfRLIndex, SF, STfR and red cell indices to classify participants into ID and non-ID. Statistical level of significance was set at $\leq 0.05$.

\section{Results}

A total of 210 participants, representing $99.1 \%$ of targeted sample size were enrolled in the study with females constituting $153(72.9 \%)$ (Table 1$)$. The overall mean \pm SD age was $16.2 \pm 1.9$ years. The mean \pm SD for HCT, MCV, MCH, STFR levels and STfLF-index were $0.40 \pm 0.35 \mathrm{~L} / \mathrm{L}, \quad 84.0 \pm 5.6 \mathrm{fL}, 26.5 \pm 2.1 \mathrm{pg}$, $3.1 \pm 1.6 \mathrm{mg} / \mathrm{L}$ and $1.8 \pm 1.1$ respectively. Median (IQR) SF level was 60.5(84.0) ug/L.

Based on the STfLF-Index, STfR, SF and red cell indices, $61.9 \%(130 / 210), 76.2 \%(160 / 210), 3.3 \%(7 / 210)$ and $53.3 \%$ $(112 / 210)$ had iron deficiency, respectively. Soluble transferrin receptor (STfR) detected a statistically higher percentage of students with ID compared to the other biomarkers (Table 2). Assessment of agreements in classification (ID versus No ID) revealed that only STfR and STfLF-Index had good agreement (concurrence) (Table 3).

\section{Discussion}

There have been numerous advances in laboratory tests for assessing iron status with each test directed at different phases of iron metabolism. An understanding of the comparative ability of these tests to detect iron deficiency is still a challenge and studies are few. ${ }^{17,18}$ This study therefore assessed inter-rater agreements between red cell indices (MCV and $\mathrm{MCH}$ ), SF, STfR and STfLFIndex in diagnosing Iron deficiency.

This study demonstrated that red cell indices detected a higher proportion of ID compared to serum ferritin. Even though both red cell indices and serum ferritin levels serve as screening tests in assessment of iron status because they may be low in thalassemias, sideroblastic anemia, anemia of chronic inflammation and lead poisoning. ${ }^{19}$

The comparable rates of ID detection between red cell indices and STfLF-Index demonstrated by Z-tests of proportions in this study has to be interpreted with caution. This is because of the poor inter-rater agreement between these tests demonstrated in this study. Whereas the former is a global measure, the latter is a more specific paired-observation statistic that assesses how a pair of tests rates the individual patient's iron status across the complete range of observations. ${ }^{20}$ Although red cell indices are often used especially in resource constrained settings this limitation should always be borne in mind.

The STfLF-Index cutoff used in this study has been demonstrated to have sensitivity and specificity of $100 \%$ and $98 \%$ respectively. ${ }^{16}$ We found that the STfLF-Index was able to detect iron deficiency in more than half of the participants followed by red cell indices and then SF. There was poor agreement between the STfLF-Index and other markers in classifying the participants in this study into iron deficient and non-iron deficient. These findings seem to be in consonance with the reports that showed STfLFIndex has powerful diagnostic accuracy in differentiating iron deficiency anemia from mixed iron/other nutrients deficiency anemia and anemia of chronic disease..$^{21-23}$
Although SF estimation is a commonly employed tool in evaluating iron status, our study found that it detected fewer ID cases when compared with red cell indices. This is an unexpected finding because iron stores have to be depleted before red cell indices $(\mathrm{MCV}$ and $\mathrm{MCH})$ start to decline. ${ }^{24}$ Alternatively, it may suggest that these participants have elevated SF levels due to other conditions, which this study did not assess.

The comparative advantage of STfR over SF has been demonstrated to be due to the latter's role in the acute phase response to inflammation in chronic disorders. Kari et al. evaluated STFR and STFR/ferritin index and concluded that serum ferritin may provide a rational basis for identifying IDA, but all factors affecting ferritin levels have to be considered. ${ }^{25}$ Alan et al. in a different study found the sensitivity of STFR to be $92 \%$ and specificity of $84 \%$ while serum ferritin has specificity and sensitivity of $92 \%$ and $98 \%$ respectively. ${ }^{26}$ They therefore opined that STFR evaluation has no additional value to serum ferritin estimation in assessing IDA. Hanif et al. in Pakistan evaluated the diagnostic efficacy of STFR and found both the sensitivity and specificity of STFR in IDA to be $100 \%$ while in Anaemia of Chronic Disorders (ACD), they were $66.6 \%$ and $100 \%$ respectively. ${ }^{27}$

The WHO suggests that STFR be used in settings of chronic inflammation. ${ }^{10}$ All these findings support the concept that individually no tool is ideal, but combining STFR and SF as STfLF-Index has significantly addressed the drawbacks of individual tools and has improved the diagnostic efficacy.

The good agreement between STfR and STfLF-Index in discriminating between ID and No ID in this study may mean that in situations where patients can only afford one assay then the STfR assays should be used especially since it is not affected by inflammation. ${ }^{10}$

\section{Conclusions}

STfR and STfLF-Index have similar ability in classifying iron status. They should therefore be considered in evaluating patients for iron deficiency, particularly in settings of chronic inflammation.

\section{References}

1. Hoffbrand AV, Hershko C, Camaschella C. Iron metabolism, iron deficiency and disorders of haem synthesis. In: Hoffbrand A, Catovsky D, Tuddenham E, eds. Postgraduate Haematology. 6th ed. Massachusetts USA: Blackwell Publishers Ltd; 2011. p. 26-46.

2. Tatala S, Svanberg U, Mduma B. Low dietary iron availability is a major cause of anemia: a nutrition survey in the Lindi District of Tanzania. Am J Clin Nutr 1998;68:171-8.

3. Esan AJ. Prevalence and Evaluation of Iron Deficiency Anemia in Anemic Hospitalized Patients in Osogbo, Nigeria. J Hematol Blood Transfus Disord 2016;3.

4. Hoffbrand AV, Moss PAH. Hypochromic anaemias. In: Essential Haematology. 6th ed. Masachusetts, USA: Blackwell Publishers Ltd; 2011. p. 33-44.

5. Ernest B. Disorders of Iron Metabolism. In: Kenneth K, Marshall AL, Ernest B, et al, eds. Williams Haematology. 8th ed. New York USA: The McGraw-Hill Ccompanies Inc; 2010. p. $567-8$.

6. Aimone-Gastin I. [Biochemical markers of iron status]. 
Nephrol Ther [Internet]. 2006;2:S321-6.

7. Brugnara C. Iron deficiency and erythropoiesis: new diagnostic approaches. Clin Chem 2003;49:1573-8.

8. Kawthalkar SM. Anaemias due to impaired red cell production. Iron Deficiency Anaemia. In: Essentials of Haematology. 2nd ed. New Delhi: Jaypee Brothers Medical Publishers (P) Ltd; 2013. p. 71-120.

9. Cheesbrough M. District Laboratory Practice In Tropical Countries Part 2. 1st ed. Cambridge: Cambridge University Press; 2006. 310-312 p.

10. World Health Organization. Serum ferritin concentrations for the assessment of iron status and iron deficiency in populations. Vitamin and Mineral Nutrition Information System. [Internet]. World Health Organization. Geneva: World Health Organization; 2011. 1-5 p. Available from: http://www.who.int/vmnis/indicators/serum_ferritin.pdf

11. Akinyemi O, Ibraheem AG. Assessment of Nutritional Status of Queens College Students of Lagos State, Nigeria. Pakistan J Nutr 2009;8:937-9.

12. Infusino I, Braga F, Dolci A, Panteghini M. Soluble Transferrin Receptor (sTfR) and sTfR/log Ferritin Index for the Diagnosis of Iron-Deficiency Anemia A Meta-Analysis. Am J Clin Pathol 2012;138:642-9.

13. Angeles Vazquez Lopez M, Molinos FL, Carmona ML, et al. Serum Transferrin Receptor in Children: Usefulness for Determinating the Nature of Anemia in Infection. J Pediatr Hematol Oncol 2006;28:809-15.

14. Abramson JH. WINPEPI updated: computer programs for epidemiologists, and their teaching potential. Epidemiol Perspect Innov 2011;8:1.

15. World Health Organization. Haemoglobin concentrations for the diagnosis of anaemia and assessment of severity [Internet]. World Health Organization. Geneva, Switzerland: World Health Organization; 2011.

16. Lee EJ, Oh E-J, Park Y-J, et al. Soluble transferrin receptor (sTfR), ferritin, and sTfR/log ferritin index in anemic patients with nonhematologic malignancy and chronic inflammation. Clin Chem 2002;48:1118-21.

17. Gwetu TP, Chhagan MK, Taylor M, et al. Anaemia control and the interpretation of biochemical tests for iron status in children. BMC Res Notes 2017;10:163.

18. Pfeiffer CM, Looker AC. Laboratory methodologies for indicators of iron status: strengths, limitations, and analytical challenges. Am J Clin Nutr 2017;106:1606S-64.

19. Andrews NC. Iron deficiency and related disorders. In: Greer JP, Foerster J, Lukens JN, editors. Wintrobe's Clinical Haematology. 11th ed. Lippincott Williams and Wilkins Ppublishers; 2003. p. 794-819.

20. Laerd Statistics. Cohen's kappa in SPSS Statistics - Procedure, output and interpretation of the output using a relevant example. Laerd Statistics [Internet]. Statistical tutorials and software guides. 2015 [cited 2018 Jun 8]. Available from: https://statistics.laerd.com/spss-tutorials/cohens-kappa-in-spssstatistics.php

21. Wish JB. Assessing iron status: Beyond serum ferritin and transferrin saturation. Clin J Am Soc Nephrol 2006;1:S4-8.

22. Punnonen K, Irjala K, Rajamäki A. Serum transferrin receptor and its ratio to serum ferritin in the diagnosis of iron deficiency. Blood 1997;89:1052-7.

23. Genc S, Erten N, Karan MA, et al. Soluble transferrin receptor and soluble transferrin receptor-ferritin index for evaluation of the iron status in elderly patients. Tohoku J Exp Med 2004;202:135-42.

24. Naghii MR, Abbasali Imam F. Correct assessment of iron depletion and iron deficiency anemia. Nutr Health 2006;18:133-9.

25. World Health Organization. Iron deficiency anaemia: assessment, prevention and control. WHO. 2017. Available from: http://www.who.int/nutrition/publications/micronutrients/anae mia_iron_deficiency/WHO_NHD_01.3/en/

26. Mast AE, Blinder MA, Gronowski AM, Chumley C SM. Clinical utility of the soluble transferrin receptor and comparison with serum ferritin in several populations. Clin Chem 1998;44:45-51.

27. Hanif E, Ayyub M, Anwar M, et al. Evaluation of serum transferrin receptor concentration in diagnosing and differentiating iron deficiency anaemia from anaemia of chronic disorders. J Pak Med Assoc 2005;55:13-6. 